\title{
Representaciones en torno a los empleados públicos en Chile, 1880-1920
}

\author{
Diego Barría Traverso ${ }^{1}$ \\ Recibido: 10 de octubre de 2016 - Aceptado: 28 de octubre de 2016
}

\begin{abstract}
Resumen
Este artículo analiza otro tipo de discusión en torno a los empleados públicos: aquella que se centró en cuestiones de carácter social. Lo que se busca encontrar en el período 1880-1920 es un conjunto de representaciones que permitan asignar un lugar a los empleados públicos dentro de la estructura social. A partir de la revisión de novelas sobre el período, prensa satírica y ensayos que analizaron la llamada "crisis del centenario", se muestra que los empleados públicos eran un sujeto social diferenciado de la elite. Igualmente, se destaca que al empleado se lo caracterizaba como un tipo con una serie de vicios asociados a la identidad chilena. Se argumenta que la cantidad de críticas en torno a los empleados presentadas en diversos medios escritos durante la época (novelas, prensa y ensayos) muestran que estos fueron constituyéndose, de forma creciente, en actores relevantes de la vida nacional.
\end{abstract}

Palabras clave: Empleados públicos, clase media, administración pública, Chile.

\section{Representations about Public Employees in Chile, 1880-1920}

\begin{abstract}
This article analyzes another type of discussion about public employees: the one that focused on social issues. What is sought to be found in the period 1880-1920 is a set of representations that allow to assign a place to public employees within the social structure. From the review of novels on the period, satirical press and essays that analyzed the so-called "crisis of the centenary", it can be seen that public employees were social subjects differentiated from the elite. Equally, it is emphasized that the employee was characterized as a type with a series of vices associated with the Chilean identity. It is argued that the number of critics about employees presented in several written media
\end{abstract}

1 Chileno. Doctor en Historia. Académico del Departamento de Gestión y Políticas Públicas, Universidad de Santiago de Chile. E-mail: diego.barria@usach.cl. Este artículo es resultado del proyecto Fondecyt de Iniciación $N^{\circ} 11140348$, Reforma administrativa del Estado chileno entre 1920 y 1931: ¿Nuevos proyectos o herencias del pasado? 
during the time (novels, press and essays) show that they were increasingly becoming relevant actors of national life.

Keywords: Public employees, middle class, public administration, Chile.

\title{
Representações em torno aos funcionários públicos no Chile, 1880-1920
}

\begin{abstract}
Resumo
Este artigo analisa outro tipo de discussão em torno dos funcionários públicos: aquele que se centrou em questões de caráter social. 0 que se procura encontrar no período 1880-1920 são um conjunto de representações que permitam definir um lugar aos funcionários públicos dentro da estrutura social. A partir da revisão de romances sobre o período, imprensa satírica e ensaios que analisaram a "crise do centenário", mostra-se que os funcionários públicos foram sujeito social diferenciado da elite. Argumenta-se que a quantidade de críticas em torno aos funcionários públicos apresentadas em diversos meios escritos durante a época (romances, jornais e ensaios) mostra que estes foram se tornando, cada vez mais, em atores relevantes da vida nacional.
\end{abstract}

Palavras-chave: Funcionários públicos, classe média, administração pública, Chile.

Aunque generalmente se identifica 1925 como el momento en el que el aparato administrativo chileno comenzó a crecer y tener un rol importante en la sociedad (véase, por ejemplo, Ibáñez, 2003), en las décadas anteriores diversos actores daban cuenta de la presencia del Estado en la sociedad. En especial, surgió una gran cantidad de críticas en torno a quien encarnaba esa presencia estatal: el empleado público.

Entre 1880 y 1919, la participación del empleo público civil en la población económicamente activa pasó desde un 0,28\% a un 1,96\% (Barría, 2015). Es decir, tras 39 años, el tamaño del empleo público creció siete veces. Por ello, no resulta extraño que se instalara en diversos círculos una dura crítica a lo que se llamó la empleomanía. Se consolidó en la opinión pública una imagen de proliferación de puestos inútiles dentro de la administración del Estado. Además, se creía que estos eran obtenidos por los protegidos de las autoridades políticas, como forma de pago por favores electorales.

Esta impresión generó un malestar generalizado en la prensa. Los más críticos a la forma de seleccionar empleados, afirmaban que a la administración no llegaban las personas más idóneas. Ello llevó a que se desarrollara una activa discusión en torno a las capacidades requeridas para ocupar un empleo público y que fue abordada en los ámbitos políticos (véase, por ejemplo, El Independiente, 7-X-1886; El Mercurio, 12-X-1886; La Libertad Electoral, 17VI-1887 y 2-VII-1887) y académicos (véase Barría, 2009). 
Este artículo analiza otro tipo de discusión en torno a los empleados públicos: aquella que se centró en cuestiones de carácter social. Lo que se busca encontrar en el período 1880-1920 es un conjunto de representaciones que permitan asignar un lugar a los empleados públicos dentro de la estructura social. Los pocos estudios existentes hasta este momento sobre los orígenes sociales de los empleados públicos en la segunda mitad del siglo XIX han planteado que en la administración comenzaron a llegar "hombres nuevos" (de clase media) (De León, 1964; Stabili, 2000). En línea con esto, se plantea que existen elementos que permiten dar crédito a la idea de que los empleados públicos provenían de la clase media. A la diferencia de ingresos con respecto a la elite y las clases populares, documentada en Barría (2015), es posible advertir que la elite veía a los empleados como un otro, que no compartía ni sus hábitos ni el "perfume aristocrático". Barros y Vergara (1978) plantean que lo que distinguió a la elite de la época fue su gusto por el ocio y su rechazo al trabajo. Al indagar sobre estas cuestiones, se mostrará que esta cuestión separaba a los miembros de la elite con los empleados públicos, cuya identidad era, precisamente, su carácter de trabajadores. Igualmente, se mostrará que tanto los medios de prensa como intelectuales de la época veían en el empleado a un tipo con una serie de vicios. Una cuestión interesante es que dichos vicios no eran considerados propios de los empleados, sino que habrían formado, de acuerdo con varios autores, parte de la identidad chilena. Tanto esta cuestión como la gran cantidad de referencias disponibles muestran que los empleados fueron constituyéndose, de forma creciente, en actores relevantes de la vida nacional.

El trabajo se divide en cuatro secciones. En la primera, se analizan algunas novelas que describen el Chile de la época, especialmente rasgos propios de las relaciones sociales. En la segunda sección se estudia cómo se veía a los empleados públicos en la prensa satírica. Ya que estos periódicos buscaban atacar al adversario político a través del humor, se constituyen en una fuente ideal para identificar representaciones ricas en la descripción de atributos. Y, de hecho, el empleado público era un personaje sobre el que se hablaba constantemente en estos medios. En la tercera sección se estudia la opinión sobre el rol de los trabajadores del Estado, expresada por un grupo de intelectuales críticos con la situación del país durante la década de 1910, quienes han sido identificados por Gazmuri (2001) como los "ensayistas de la crisis". Finalmente, se entregan algunas conclusiones.

\section{El empleado como un "otro" social}

Como muestran Barros y Vergara (1978, 48-51), para la elite chilena de finales del siglo XX y comienzos del XX, el trabajo era algo alejado de sus preocupaciones y de su identidad. Destacan que el ocio era un factor central 
en la identidad aristocrática, junto con el hecho de que "el trabajo oficinesco es suplicio siempre renovado". Este desprecio al trabajo y la predilección por el ocio actuó como el factor de diferenciación de la elite social en el 1900. Tanto Barros y Vergara $(1978,102)$ como Encina (1972 [1911], 68) hacen referencia a que ciertas personas (los "venidos a menos") ingresaban al mercado laboral únicamente tras perder fortunas o fracasar en los negocios. En esos casos buscaban un empleo público para hacer frente a su nueva situación económica.

El rechazo de la elite de la época al trabajo es graficado en varias novelas escritas a comienzos del siglo XX. En Casa Grande, de Luis Orrego Luco, el protagonista (Ángel Heredia) formaba parte de una familia aristocrática que llegó a Chile a pelear la Guerra de Arauco. El viejo espíritu colonial hacía a los jóvenes de las familias de la alta sociedad exagerar el prestigio y valor de su familia, "enseñándoles a considerar como denigrantes casi todas las formas de la actividad humana, en el comercio y en el trabajo". Estos jóvenes solamente entraban a la universidad a estudiar leyes o medicina, obteniendo el grado entre "fiesta y fiesta" (Orrego Luco, 1983 [1908], 98). Este desprecio expreso a ciertas actividades también lo manifestaba uno de los protagonistas de Cuando mi Tierra era niña, de Inés Echeverría. Juan Irisarri era un joven heredero de un mayorazgo de Castilla, que había elegido estudiar leyes, pues, en su visión, no existía otra carrera adecuada a su rango. Otras profesiones, como la ingeniería o la medicina eran, en la visión de Irisarri, buenas para ganapanes (Echeverría, 1942, 133).

Heredia era un fiel exponente del desprecio al trabajo. De hecho, mostraba una "antipatía por el esfuerzo continuado y modesto del trabajo rudo... desdén de ciertos oficios y de ciertas clases [y un] fanatismo unido al horror de la cultura científica" (Orrego Luco, 1983 [1908], 91). Al casarse con Gabriela Sandoval, administró la herencia de su esposa, invirtiendo en acciones de la Bolsa. Vivió un tiempo de bonanza, haciéndose fama por las altas ganancias que había logrado; sin embargo, a partir de la baja de unas acciones de una empresa de papel que, supuestamente, se dedicaría a la extracción de inexistentes sales potásicas en el sur, Heredia comenzó a tener problemas para solventar los gastos de su mujer. Este escenario colocó en jaque al personaje. El orgullo aristocrático de Heredia lo hacía incapaz de trabajar en ciertas ocupaciones. Solo veía como opciones la agricultura y el comercio. Sus amigos se habrían burlado si hubiese montado, por ejemplo, un almacén.

Eduardo Biset, protagonista de El inútil, de Joaquín Edwards Bello, también mostraba un rechazo al trabajo. Habiendo dejado el colegio antes de terminar sus estudios de Humanidades, nunca se desempeñó en ninguna ocupación. No quería "pasarse la vida en un sillón de una oficina oscura" (Edwards Bello, 2004 [1910], 187), ni tampoco estar "detrás de 
un mostrador o en una oficina, ganando menos que un mozo de restaurante" (p. 231).

Una segunda cuestión que distinguiría al empleado de la elite se refiere al lugar que cada uno de estos grupos ocupaba en la estratificación social de finales del siglo XIX y comienzos del XX. Según cuentan estas novelas, los círculos sociales, definidos en ellas como aristocráticos, se diferenciaban claramente del resto de la sociedad. Orrego Luco describe una escena en una noche de pascua del 1900 y tanto en la Alameda de la siguiente manera. En la calle se encontraba un grupo de mujeres jóvenes, entre ellas, las hermanas Magdalena y Gabriela Sandoval, que formaban parte de una familia de la elite santiaguina de la época. Alrededor de ellas se encontraban:

"camareras, obreros, comerciantes de menor cuantía, empleados modestos, gente de clase media, militares y campesinos de manta [Entre ellos estaban las jóvenes, quienes] sabían conservar el porte de gran tono, el perfume aristocrático, el no sé qué refinado e inimitable que constituye la fuerza y la esencia de las clases sociales superiores -esencia tan perdurable y poderosa que no han sido parte a borrarla ni las sangrientas sacudidas de la revolución francesa ni las guerras civiles ni el avance de la democracia i las invasiones omnipotentes del dinero" (Orrego Luco, 1983 [1908], 8-9).

De acuerdo con Inés Echeverría, la sociedad estaba dividida entre aristocracia y pueblo, existiendo una clase intermedia que estaba conformada con "lo mejor del pueblo y las familias venidas a menos y señoras vergonzosamente allegadas a casas grandes, o por hombres empobrecidos o viciosos" (Echeverría, 1942, 121). Dentro de esta estructura social, ¿qué lugar ocupaba el empleado público? Revelador resulta el relato del aristócrata Juan Irisarri sobre la participación de los empleados públicos en un "Baile Oficial" que ofreció el Presidente de la República, José Joaquín Pérez. Al respecto, decía:

"todos los empleados públicos con sus familias (...) el presupuesto en masa. Los porteros de oficinas, los "matanceros" del cuadro, los ayudantes del hospital, los ferrocarrileros, palanqueros, etc., todos los agentes de policía a excepción de los vigilantes.

Unos siúticos caritristes, o cariacontecidos, que no conocían a nadie y en quienes nadie tampoco reparaba (...) ofuscados por la luz, con las colas de los fraques prestados o arrendados (...) colgantes o suspendidos. Reventaban dentro de la ropa, o se les arrugaban como bolsas vacías los trapos sobre el cuerpo. Los guantes les ponían las manos tiesas o les dejaban dedos en huelga" (Echeverría, 1942, 268-269). 
Parece ser que, al menos en la década de 1860, para la elite los empleados públicos eran personas con las que coincidían en ciertos espacios sociales, pero al mismo tiempo eran invisibles, pues nadie reparaba en ellos. Finalmente, la calificación "siútico" termina por colocar fronteras entre la elite y los empleados nombrados.

No obstante, los ridiculizados por Irisarri formaban parte de los empleos de más bajo rango en la administración. El cronista no nombra, por ejemplo, a oficiales. De hecho, en varias novelas se mencionan a empleados públicos que conviven con la elite, como Jacinto Peñalver (Orrego Luco, 1983 [1908], 32-33), o Emilio Mendoza, cuya familia, plegándose a los gobiernos, obtenía buenos sueldos en ciertos empleos (Blest Gana, 2005 [1862], 20).

También es posible encontrar diferencias entre los empleados y el mundo popular, por ejemplo, en los sueldos (Barría, 2015). Otra distinción tiene que ver con el estatus de cada grupo dentro de la sociedad. Para el caso particular de los empleados públicos chilenos existe un pasaje de novela que permite avanzar en esa dirección. En El Inútil de Joaquín Edwards Bello, Eduardo Biset, tras dejar el colegio, comenzó a visitar frecuentemente un lugar en el que gente sencilla almorzaba y bebía alcohol. El joven se hizo frecuente del local, perteneciente a doña Tránsito -una mujer de pueblo que mantenía su familia con el negocio-. Un día, Aurora, la hija de la dueña, le preguntó a Eduardo en qué trabajaba. Biset mintió y dijo que era empleado de un ministerio. Esta ocupación generó inmediatamente respeto entre esas mujeres, pues "Entre esas gentes sencillas el ser empleado en algo así que tenga que ver con el Gobierno es una cosa muy grande, colosal, y Eduardo fue mirado desde ese día como un ser extraordinario" (Edwards Bello, 2004 [1910], 50). Este prestigio alcanzaba, incluso, para que doña Tránsito y Aurora, fervientes católicas, aceptaran las ideas de Eduardo en contra de la Iglesia. Si bien lo que decía Biset contrariaba sus creencias, Aurora consideraba que sus planteamientos, por venir de un empleado ministerial, "debían ser buenos" (Edwards Bello, 2004 [1910], 56).

Las representaciones sociales provenientes de las novelas analizadas muestran que el mismo hecho de emplearse para ganar la vida era una cuestión que no iba de la mano con el orgullo social que tenían los sectores acomodados de la sociedad. Por lo tanto, los empleados no podrían pertenecer a la elite. Sin embargo, esta afirmación no puede ser tajante. Como se muestra en este mismo capítulo, existía en la administración la figura del "hijo de padre rico", que sí optaba por trabajar en las oficinas públicas, quizás por el afán de los padres, por ejemplo, el de Juan Irisarri, porque sus hijos se ocuparan en algo.

Lo que sí queda claro es que, aun cuando sus hijos pudieran llegar a las oficinas, ello no era impedimento para que la elite considerara a los empleados 
públicos como parte de un sector social distinto. Un elemento diferenciador claro era el "perfume aristocrático", del cual los empleados, aun yendo a los mismos bailes, y con las mismas ropas de la elite, carecían.

\section{Los empleados públicos vistos en la prensa satírica}

"La empleomanía tiene su razón de ser en Chile"

Hacia 1884, el periodista Juan Rafael Allende decía ver nacer una nueva profesión, la de empleado público. Las personas que se dedicaban a ella eran hijos de "hacendado, minero, capitalistas y usureros". Las colocaciones en la administración eran conseguidas por los padres cuando no lograban que "sus vástagos estudien el arte de matar a dragazos o de enredar pleitos". Según el articulista se vivía en una época en que:

"Un rosario de decretos creando oficinas, empleados, sueldos, me asegura que antes de mucho hasta yo seré empleado público. Aun contra mi voluntad, viviré del Presupuesto; pues cuando llueve todos se mojan, i hace dos administraciones que no escampa" (Padre Padilla, 4-X-1884).

Lo escrito por Allende viene a destacar una creencia instalada, no solo en la prensa satírica, sino que también en la literatura, ensayos de intelectuales y escritos de académicos, respecto a que el acceso al empleo público tenía directa relación con contar con "santos en la corte" 2 o con la existencia de personas que hacían empeños por ciertos protegidos (véase Barría, 2009).

La empleomanía era un fenómeno cuya existencia no se discutía mayormente por la prensa y por la intelectualidad en el período: se la daba por hecho. Diferentes medios intentaron explicar sus causas y al menos tres teorías se presentaron.

La primera venía a relacionar la empleomanía con la forma de ser del chileno. Se decía que era una "enfermedad a la sangre", que se presentaba cada cinco años, con cada cambio de gobierno, o con la aparición de una crisis política. La empleomanía era un rasgo característico del chileno, el que, según un articulista de El Fígaro, nacía para ser empleado público. El medio graficaba la situación, diciendo que "La ambición del empleo es en nosotros lo que en los españoles es la afición a los toros i en los ingleses la afición al turf, al whyski [sic] i al lado i lado". La razón de esta enfermedad

2 A modo de ejemplo de referencias al tema en Padre Padilla (29-XI-1884; 29-IX-1885; $17-$ II-1887; 29-IX-1888; 25-V-1889). 
era la flojera nacional y la costumbre de no hacer nada, tal cual un empleado público (El Fígaro, 30-IX-1901).

La segunda explicación achacaba la avidez de empleos al mal ejemplo de los aristócratas, quienes se repartían los mejores puestos de la administración. Ello provocaba, según esta interpretación, una imitación de las clases medias y bajas, peleándose los "mendrugos que raras veces dejan aquellos en su opípara mesa de pensionistas del Estado". La miseria producida por la voracidad oligárquica llevaba a la clase media y baja al empleo estatal, pues el gasto del presupuesto incapacitaba a estos grupos para ganarse la vida por sus propios medios (Poncio Pilatos, 13-IV-1899).

Esta situación lleva a la tercera explicación. El que el presupuesto fuese socavado, año a año, por oligarcas, limitaba toda opción de fomentar industrias. Ello provocaba, según Juan Rafael Allende, que:

"en ninguna parte como en Chile tiene más razón de existir la empleomanía, porque vuelvo a repetir lo que otras veces he dicho, en Chile solo circulan los millones de los Presupuestos. Sin el fisco nos moriríamos de hambre (El Pedromón, 29-VII-1901).

Las querellas que aparecían en la prensa de la época se enfocaban, principalmente, a una disputa de carácter político-partidista. Eso se grafica en el hecho de que el nepotismo haya sido una de las principales acusaciones políticas entre rivales durante el siglo XIX (Góngora, 1986, 56). En el período de Balmaceda, la familia Toro - de la cual provenía la esposa del Presidentefue acusada de recibir empleos y negocios ventajosos con el Estado (Padre Padilla, 29-IX-1885; 29-IX-1888).

Hacia 1901, el Presidente Germán Riesco también fue cuestionado porque, según se decía, a pesar de llegar a La Moneda como parte de un "movimiento regenerador i honrado", cuyo objetivo era "depurar la administración", terminó, al igual que los presidentes que lo precedieron, haciendo un gobierno que tenía una corte de personas que buscaban "entrar a seco en las arcas fiscales i a bayoneta calada en el presupuesto de la nación", en busca de empleos "para comer, para medrar, para subir a costillas del pueblo" (El Fígaro, 11-XI-1901)3. Se planteaba que, anteriormente, Jorge Montt y Federico Errázuriz habían socavado los caudales públicos, colocando a sus familiares en puestos públicos (El Pedromón, 29-VII-1901).

3 Otras críticas del mismo medio sobre el uso particular de los recursos fiscales aparecen en la nota titulada "Negocitos Fiscales", en El Fígaro, 19-I-1903. 
Otro aspecto discutido fue la forma de hacer nombramientos. No solamente se discutieron consideraciones de carácter político, sino que también surgió una discusión sobre qué clases sociales debían ocupar los empleos. Allende se preguntaba si no era una inequidad que desde los mejores empleos hasta los oficiales de pluma fuesen ocupados por los "hijos de". El periodista proponía que se abrieran concursos públicos para proveer empleos, de manera que "todos cuchareen en las ollas de la gran piñata" (El Pedromón, 29-VII-1901). "Pudiendo proveerse casi todos los puestos a concurso" decía Allende, ello no se hacía:

"para escluir sistemáticamente a toda una clase social al acceso de ellos, la que por su aplicación al estudio i el trabajo, i la consiguiente competencia, como tambien por su moralidad i honradez, seria ventaja i garantía para el Estado" (Padre Padilla, 25-IV-1889).

La identificación que hacía Allende de los puestos superiores hasta los oficiales de pluma, como reservados para los "hijos de", es coincidente con el relato de Juan Irisarri, citado anteriormente, en el que el joven aristócrata se burlaba únicamente de los empleados fiscales de menor rango.

Al referirse a ciertas posiciones en el Registro Civil, Allende señalaba que éstas, al tener sueldos equivalentes a ración de hambre, no iban a ser ocupadas por el "señorito tal o cual sin otro título que el de ser hijo del Presidente, de los Ministros o de algun senador capitalista" (Padre Padilla, 29-XI-1884). Esa "juventud dorada" se encontraba en los ministerios (Padre Padilla, 25-IV-1889) ${ }^{4}$.

Estos relatos dan luces respecto a la posibilidad de que hayan existido espacios administrativos separados; unos para la clase alta y otros para la clase media. El tema no es menor, pues los relatos de Allende hacen plausible la idea de que la llegada de "nuevos hombres" (véase De León, 1964; Stabili, 2000) se haya dado de manera gradual. Esto implicaría que el período en cuestión se habría caracterizado por representar una transición, en lo que a orígenes sociales de los empleados se refiere, cuya primera etapa significó la convivencia en las oficinas públicas entre la "juventud dorada" y sectores medios de la sociedad.

El hecho de que se comience a reclamar para la clase media los puestos administrativos da cuenta del interés de esos sectores por entrar a las oficinas públicas, y hace presumible que ello era posible, toda vez que ya era un tema digno de ser discutido en la opinión pública.

4 En otro artículo, Allende se refería a la costumbre de veranear como algo característico de aristócratas, algo que, entre otras personas, "queda para los empleados de los Ministerios, que, con suculento viático sacado del estracto del pueblo trabajador, van a tomar baños de mar" (Padre Padilla, 13-IX-1888). 


\section{Sujeción, capacidad y costumbres de los empleados públicos}

Los mecanismos de provisión de empleos ayudaron a formar una imagen sobre el empleado público que se caracterizaba por al menos dos cuestiones: 1) Ser una persona que era dependiente de la autoridad de turno y los políticos, en general; 2) Ser un incompetente en el trabajo, junto con tener algunos vicios como, por ejemplo, ser un holgazán que rara vez acudía a su trabajo (y, si lo hacía, no era a trabajar).

Los empleados públicos eran percibidos como un grupo de personas que tenía una dependencia directa respecto a la autoridad. Por ejemplo, hacia 1901 un medio destacaba el que cada cambio de gobierno implicaba remover casi la totalidad de la administración. Ello hacía que:

"El empleado que ve que sus cinco años de sueldos i de sabor fiscal van a terminar, se ve obligado para no caer a aferrarse al candidato a la Presidencia que tenga mas probabilidades i a intervenir a favor de él" (El Fígaro, 7-X-1901).

Las caricaturizaciones destacaban al Presidente de la República como el gran dispensador de empleos. Por ejemplo, una caricatura publicada en la década de 1880 mostraba al Presidente Balmaceda rociando un árbol lleno de frutos -puestos en la administración, como el de gobernador o juez-con una regadera que decía "Olvido completo para mis adversarios" (Padre Padilla, 14 de noviembre de 1885. Véase también nota del 10-XII-1886).

En otra caricatura, una persona solicita un empleo al Presidente Santa María, recibiendo un "No" como respuesta. Posteriormente, Santa María niega el empleo frente al padre y la madre del aspirante. Al asistir la hermana del muchacho, el Presidente se arrodilla frente a ella, ofreciéndole banda presidencial para su hermano (Padre Padilla, 25-IX-1884). Este grabado, junto con dar a entender la afición de Santa María por las mujeres, destacaba el papel del Presidente de la República como la persona facultada para dar empleos.

Hacia 1901, en tanto, el Presidente Riesco aparecía, con brazos cruzados, en una caricatura, rodeado por un grupo de hombres -más pequeños que él- con sombrero y terno, solicitándole un empleo (El Fígaro, 10-X-1901).

Un año antes de la guerra civil de 1891, los medios opositores ironizaban sobre las razones por las que se despedía a ciertos empleados públicos. Para El Fígaro tener parientes en la oposición, en la Iglesia Católica o en los medios de prensa opositores era razón de despido (El Fígaro, 13-II-1890). 
La sujeción fue caricaturizada en Poncio Pilatos con un grabado en el que un grupo de ovejas (empleados) era llevado a pastar a La Moneda. El texto que acompañaba el dibujo destacaba que, llegado marzo, era necesario organizar el rodeo de los empleados.

"Ya es llegado, pues, el tiempo

En que la recua de ociosos

Que empleados son de Gobierno,

I que hoy andan solazándose

Por montañas i potreros,

Vuelvan al viejo corral

En que se les da buen pienso

Porque brazo sobre brazo

Se pasean de enero a enero"

(Poncio Pilatos, 7-|II-1895).

Las relaciones de sujeción también se daban entre jefes de oficinas y sus empleados. Por ejemplo, al ser despedido un Director de Explotación de Ferrocarriles del Estado, un medio lo caricaturizó en un grabado en el que aparecía, con cara triste, diciendo, "Queridos parientes, siervos, Me van a quitar el puesto. Llorad lágrimas de sangre, porque perdeis pan i perro" (El Fígaro, 24-XI-1902).

De acuerdo con los medios satíricos, cada cambio de gobierno suponía la renovación del personal administrativo. En una caricatura que mostraba la llegada de Germán Riesco a La Moneda en 1901, perros y posiblemente empleados, arrancaban con caras asustadas de la casa de gobierno ( $E$ l Fígaro, 9-IX-1901). Otro ejemplo, fue el intento de un Ministro de Obras Públicas, Abraham Gacitúa, de despedir a los empleados de la Dirección de Obras Públicas, debido al mal estado de las construcciones a cargo de la oficina. En esta ocasión, Gacitúa fue representado como Jesús expulsando a los mercaderes del templo. En una secuencia posterior de caricaturas, el intento del ministro fue representado como una campaña por sacar a ratas que se comían el erario nacional (véase El Fígaro, 4-X-1900, 10-X-1900, $11-X-1900,13-X-1900)$.

Juan Rafael Allende ironizaba, hacia 1884, sobre los requisitos que los "hijos de" debían cumplir para obtener un puesto. Su lista contemplaba cinco exigencias: saber leer y escribir, además de "Ilevar con gracia la levita, el colero, la varilla i la corbata, peinarse a la CAPOUL, saber hacer jineflexiones i... tener una decidida afición por el dolce far niente" (Padre Padilla, 4-X1884). Más allá de la ironía, Allende consideraba que lo correcto era que que los empleados fuesen nombrados por atributos como seriedad, honradez, inteligencia (Padre Padilla, 29-X-1884), además de la integridad, "buenos 
modales i, en una palabra, un alma bien puesta, no inclinada al mal ni la venganza" (Padre Padilla, 13-III-1888).

Sin embargo, no todos parecían cumplir con ese perfil y, por ello, ante errores, por ejemplo, de tipo contable, se recordaba que estos habían sido cometidos por empleados con "santos en la Corte" (Padre Padilla, 17-II1887). Existía una idea en la opinión de los medios de que "la masa de cortesanos" que buscaba empleos terminaba postergando a "servidores antiguos i meritorios" que eran arrojados a la calle sin el pan "al que tienen derecho" (El Fígaro, 11-XI-1901). Quienes iban a la "pecha" de empleos eran los "cesantes de todos los gobiernos, los truhanes, los tunos, en total, todos los holgazanes, atorrantes" (El Fígaro, 25-XI-1901).

El cuestionamiento a los méritos de los empleados protegidos por políticos llevó a poner en duda sus capacidades y desempeño. Allende decía, hacia 1895, que las oficinas públicas daban un "pésimo servicio", a causa de que los empleados se creían "el verdadero patrón". Las Oficinas de Giros Postales eran un ejemplo de mal funcionamiento. El articulista decía no saber si los empleados eran "mui incompetentes, mui estupidos o sirven borrachos sus destinos" (Poncio Pilatos, 21-III-1895). Otras actitudes de empleados, reprochadas por Allende, eran la mala educación, la falta de cortesía y el despotismo (Poncio Pilatos, 27-IV-1895). Ante estos vicios, creía conveniente llamar a concurso para llenar puestos en servicios, como la Policía de Seguridad, con bachilleres que habían interrumpido sus estudios, pero que eran "instruidos, laboriosos, honrados, inteligentes i perspicaces" (Poncio Pilatos, 13-VI-1895).

La prensa también prestó atención a la vida cotidiana de oficina. La representación del rodeo, ya vista, destacaba el hecho de que los empleados debían ser llevados al trabajo, tras haber estado solazándose (Poncio Pilatos, 7-III-1895). El hecho que se viera a estas personas como poco asiduas a trabajar llevó a que se prestara atención a sus jornadas laborales. Para Juan Rafael Allende, en los ministerios existía una "veintena de holgazanes, mocitos de la juventud dorada", cuya función en las oficinas no pasaba de conversar de una a cuatro de la tarde. Continuaba señalando que "el mas laborioso empleado fiscal trabaja 4 horas diarias, i cada día se propone un nuevo proyecto para duplicarles sus rentas" (Padre Padilla, 25-IV-1889).

El mismo Allende, durante la guerra civil de 1891, acusó a dos empleados de la Dirección de Contabilidad, Julio Palacios y Jorge Matta, de ser revolucionarios y no ir a trabajar. De los dos "bípedos", el primero iba solamente a cobrar su sueldo a fin de mes, mientras el segundo también iba ciertos días "a tomar el té de las onces, llegando a la 1 i yéndose a las 2". Estos dos personajes, sentenciaba el articulista, en lugar de ser "peladores insignes", debían agradecer que se les diese un sueldo por hacer nada (El Recluta, 23-VII-1891). 
Un año antes de la guerra, la oposición también satanizaba a los empleados de gobierno. Por ejemplo, se decía que Fanor Velasco, hacia 1890 subsecretario de Relaciones Exteriores, no trabajaba, desconocía los asuntos a su cargo y, aun así, ganaba un sueldo alto. Los opositores aseguraban que sus cinco horas diarias en la oficina las repartía de la siguiente forma: "Dos en dormir; dos en incomodar a los demas empleados i las restantes en andar. Recorre el ministerio yendo de pieza en pieza a lo menos veinte veces al día" (El Fígaro, 24-II-1890).

Diez años después, la prensa continuaba acusando a algunos empleados que llegaban a trabajar a las cuatro de la tarde, mientras otros lo hacían solamente los últimos días del mes. Se decía que pasaban los días muertos, "aumentando el abdomen a costa del erario" (El Fígaro, 16-IX-1901).

Se creía que los empleados, principalmente de los ministeriales, eran "los seres más raros del mundo" y que su única misión era "cobrar sus sueldos a fin de mes sin importarles un pito que el carro de la nación -paso do [sic] cajonesté desrielado o no". Además, se los acusaba de llevar vidas desordenadas. Se ridiculizaban sus hábitos de vida, afirmando que sus días comenzaban a las once de la mañana, hora en que se despertaban para almorzar y pasar a la casa de prenda, antes de llegar a la oficina a la una de la tarde. El resto del día seguía de esta manera:

"1.5 P.M.- Visita al jefe de la oficina con el objeto de hacerle algunos elojios, vulgo patas.

1.15 P.M.- Lectura de una novela de Paul de Kok.

2 P.M.- Pelambre jeneral en la oficina del empleado de mas confianza.

3 P.M.- Té con galletas i mantequilla.

$31 \frac{1}{2}$ P.M.- Gritos e injurias contra un ciudadano que ha ido a ver si se ha puesto providencia a una solicitud suya" (El Fígaro, 30-VII-1903).

A las cuatro de la tarde, los empleados salían de la oficina, deambulaban en la casa de prenda, pololeaban en la Plaza de Armas, asistían al teatro en la noche, desde donde salían y paseaban por cualquier parte para acostarse a las cinco de la mañana.

La imagen de un empleado ocioso dio pie, a ciertos chistes, como uno publicado en 1901, que planteaba lo siguiente:

$"-<<i$ el novio de la vecina?

¿le ha visto usted, don Ruperto?>>

$-<<$ Descansa en paz>>

$-<<$ iDiablo! ¿ha muerto? >>

-<<Hombre, no; está en la oficina>>" (El Fígaro, 30-IX-1901). 


\section{Las visiones de la elite intelectual-cultural}

\section{a. Alejandro Venegas: El empleado, un inquilino del Estado}

Bajo el pseudónimo de Doctor J. Valdés Cange, Alejandro Venegas (1910) publicó, bajo el título Sinceridad, Chile íntimo en 1910, un conjunto de cartas dirigidas al en ese momento futuro Presidente de Chile, Ramón Barros Luco. En ellas, planteaba cuáles eran las razones de la "infamante comedia" que, a su juicio, vivía el país en su primer centenario. La principal causa de la crisis moral acusada por Venegas era el establecimiento, en 1878, de la inconvertibilidad del papel moneda (p. 4).

Para Venegas, la sociedad se dividía en dos grupos. El primero, formado por "políticos especuladores i corrompidos" (p. 6), favorecidos por las políticas que se determinaban en el Congreso, y otro -el resto de la población- desfavorecido por las mismas. Si, en un principio, estos políticos eran resistidos en sus intentos de beneficiarse personalmente por el Presidente de la República, la ley de incompatibilidades de 1888, que alejó a los empleados públicos del Congreso, permitió el triunfo de sus pretensiones.

Venegas presentaba al empleado público como un personaje especialmente damnificado por los efectos de la depreciación de la moneda. Planteaba que la inconvertibilidad generaba un empobrecimiento paulatino del país al que, en general, la población podía amoldarse. Así, "el comerciante vende sus jéneros mas caros, el dueño de propiedades urbanas sube el precio de sus arrendamientos, el artesano exije una mayor suma por sus manufacturas y el jornalero cobra un mayor salario por su trabajo" (p. 37). Sin embargo, existía un "numeroso" grupo de individuos que no podía aumentar sus rentas: los empleados públicos 5 .

En opinión de Venegas, al igual como el agricultor lo hacía con el inquilino, el Estado se aprovechaba del "afecto del empleado hacia su puesto i su inutilidad para otros oficios, para apretarle la cuerda e irle convirtiendo poco a poco en paria" (p. 39). Otra prueba del desprecio hacia el empleado, según Venegas, la constituía la ley de licencias médicas vigentes en ese momento, la que solamente consideraba cuatro meses de recuperación, contemplando prórrogas - de ser necesarias- únicamente para los empleados con más de diez años de servicios, debiendo aquellos con menos tiempo, "ir a la calle o mas bien al hospital" (p. 39).

5 Durante el siglo XIX y las primeras décadas del XX, las remuneraciones de los empleados públicos eran fijadas por la ley que organizaba cada oficina. En otras palabras, un reajuste debía ser aprobado a través de ley de la República por el Congreso Nacional. 
Esta estrechez económica provocaba, en visión de Venegas, una "desmoralización profunda en los principales servicios administrativos, como ser juzgados, intendencias, gobernaciones i policías de seguridad" (p. 65). Venegas acusaba la incapacidad de funcionarios, sin delicadeza y honradez, para hacer surgir los servicios públicos, pues "ántes los malean y degradan" con su ejemplo, los mandatarios gubernativos (p. 64). En resumen, la desmoralización de los empleados estaba dada por el mal ejemplo de "los de arriba" y su mezquindad para fijar los sueldos del personal administrativo, no aminorada por las gratificaciones fijadas en años recientes.

No obstante que en Venegas existía una denuncia de las malas condiciones laborales de los empleados, esto no lo llevaba a discutir ideas dominantes como, por ejemplo, que los empleados eran muchos, incapaces y debían sus puestos a un político que los había favorecido.

\section{b. Francisco Antonio Encina: El empleado parásito}

Quizás una de las visiones más críticas sobre el empleado público de la época fue la presentada por Francisco Antonio Encina en Nuestra Inferioridad Económica (1911). De acuerdo con Encina, la empleomanía representaba la manifestación de la postración económica del país. En términos generales, la tesis de Encina plantea que la educación humanista alejaba a los jóvenes de la actividad fabril, para la que el país se habría encontrado mejor preparado. Sin embargo, esta formación llevó, según Encina, al "parasitismo", definido como la situación en la que las personas se mantenían sin generar riquezas. Las profesiones liberales y el empleo público, especialmente, fueron, según el historiador, las ocupaciones en las que los fracasados, formados por el tipo de educación imperante, iban a parar.

Para Encina, la educación humanista provocaba una preferencia de los padres de familia por que sus hijos se desempeñaran en las profesiones liberales. Según él, en una potencial encuesta a 100 padres de familia, 80 preferirían que sus hijos fuesen abogados, médicos o ingenieros. El anhelo nacional preferiría "Ser abogado, médico o ingeniero antes que agricultor; agricultor antes que comerciante o industrial; pedagogo, periodista o empleado público antes que empleado de fábrica o casa de comercio; normalista, escribiente de notaría, etc., antes que mecánico o electricista" (Encina, 1972 [1911], 56).

Para Encina, el cuadro de Chile hacia 1910 era el siguiente: desde el último tercio del siglo XIX ${ }^{6}$, el país vivía un fenómeno de parasitismo y aumento de

6 En ese mismo período, para Encina, la educación y las influencias externas habrían frenado el "favorable" desenvolvimiento moral que vivía la raza chilena. Con ello, la postración, el malestar confuso generalizado, la falta de fe en el porvenir, la pérdida de hábitos y tradiciones 
los empleos públicos, desproporcionados a las necesidades de los servicios. El candidato a empleado público era un fracasado. La mitad de los aspirantes correspondía al exceso de profesionales "y la turba enorme de los bachilleres fracasados en su intento de seguir carreras liberales". La otra mitad provenía de "los limitados horizontes de nuestra expansión agrícola, y la repugnancia por la actividad fabril y comercial de nuestra enseñanza se ha empecinado en no destruir" (p. 174). La "turba de empleados públicos" y la "espesa nube de bachilleres o casi-bachilleres ineptos y ociosos" representaban un problema para Encina, pues la tendencia hacia la empleomanía y el "profesionalismo" absorbía e inutilizaba el "corto número de hombres de carácter y talento superiores que produce nuestra sociedad" (pp. 203-204).

En resumen, como para Encina el empleo público no concurría a la producción, no era una ocupación que generara beneficios al país. No obstante, la empleomanía no era la causa de la crisis de Chile que él acusaba, sino que una consecuencia de una educación que inhabilitaba a los jóvenes para desarrollar actividades productivas.

\section{c. Tancredo Pinochet: Los vicios del empleado público}

Hacia 1915, apareció Un año empleado público en Chile. Dedicado a la juventud chilena, el libro recoge las experiencias del destacado intelectual chileno Tancredo Pinochet en la Escuela de Artes y Oficios, de la cual se hizo cargo un año antes. El texto narra la toma de posesión del cargo y los planes que desarrolló en su breve paso por la Escuela. Hace hincapié en las características que el autor atribuía a los empleados, además de destacar una serie de situaciones en las que autoridades políticas intervenían negativamente en la marcha de la Escuela.

Pinochet intentó desarrollar un estilo de gestión influido por la administración científica ${ }^{7}$, tendencia que debió haber conocido en su experiencia como administrador de una empresa norteamericana. Esta forma de pensar, que guió un proceso de reorganización administrativa dentro de la Escuela (p. 129 y ss.), hizo chocar a Pinochet con lo que él reconocía como las costumbres de la administración pública chilena.

en el gobierno y la tradición, además de un "desequilibrio agudo entre las necesidades y los medios de satisfacerlas" eran manifestaciones de la crisis moral que vivía el país (pp. 176-177).

7 El movimiento de la administración científica creció en la década de 1900, a partir de los trabajos de Frederick Taylor. Sus propulsores basaban su cientificidad en la observación y el control de los movimientos y tiempos de los operarios en los talleres. Creían que, a través de este método, podrían encontrar mejores formas de organizar el trabajo. Véase Frederick Taylor, Principios de administración científica, Buenos Aires, 1944 (1911). 
Para Pinochet, existían dos formas de entrar a la administración en la época: por competencia acreditada -mediante documentos-o por influencia política. Esto generaba, según él, lo siguiente: resultaba muy simple despedir a empleados competentes, pues no tenían padrinos. En cambio los incompetentes eran difíciles de sacar, por sus contactos (p. 217). Quien tenía una tarjeta de recomendación firmada por un ministro era un personaje arrogante, que veía ese papel como una condecoración (p. 292).

Pinochet construye en el libro una imagen del empleado público como un personaje con varios defectos. En primer lugar, lo consideraba un tipo sin fe en el esfuerzo personal, con un espíritu pasivo e indolente. Criticaba el hecho que los jóvenes prefirieran trabajar en puestos de la administración -calificados por ellos mismos como decentes- por menos dinero, en lugar de uno en que no realizara trabajos manuales o no decentes (pp. 54-60). Además, Pinochet consideraba al empleado una persona sumisa, que sabía pedir su empleo con humildad cuando había fracasado en la iniciativa privada. Las oficinas públicas eran, en su opinión:

"salas de clase con cinco horas diarias para la cátedra de la indolencia, cinco horas diarias para la cátedra de la sumisión, cinco horas diarias para la arrogancia, cinco para la pasividad, para el miedo, para la ruina. En una palabra, tantas horas diarias cuantas hay de oficina para cada uno de los vicios que concluyen con todo lo que el joven pueda tener de valor, de sueños, de ambiciones" (pp. 10-11).

Otro vicio de los empleados era el preocuparse de asuntos nimios. Pinochet acusaba la existencia de un nihilismo administrativo que hacía que en la Escuela el tema más importante por tratar, al momento de su asunción como Director, fuese el aumento del precio de la carne en la calle Franklin ( $p$. 31). Además criticaba el clasismo existente en las oficinas públicas. Acusaba que el Director anterior tenía tratos distintos para las "personas decentes" y las "ordinarias" (p. 34). Otro vicio era que los empleados tenían miedo al público (p. 35).

En resumen, de acuerdo con Pinochet, existía en el Chile de la década de 1910, una tradición administrativa que achataba el funcionamiento de las oficinas públicas. La influencia política mantenía a los incompetentes en desmedro de los competentes. Las formas de trabajo eran inadecuadas. Además, el empleado tenía una serie de vicios. Pinochet no se quedaba solamente en la incompetencia y en la forma de ingreso, sino que le achacaba una serie de actitudes negativas dentro del ámbito del trabajo. Era un personaje pasivo, cerrado frente al público, que se resistía al cambio (p. 52), y que en momentos de enfrentarse a ellos, recurría a los padrinos que lo habían colocado en sus puesto en busca de defensa. 


\section{d. Alberto Edwards Vives: El mito de la empleomanía}

Una visión diferente a las anteriores es la planteada por Alberto Edwards Vives. A partir de su experiencia como ministro de Hacienda y Director de la Oficina de Estadísticas, escribió en 1919 un artículo titulado "Los empleados públicos". En el ensayo, Edwards utiliza datos de la Lei de Presupuestos de Gastos Jenerales de la Administración Pública de Chile de 1918, para descartar la existencia de una empleomanía.

Edwards acusaba de irresponsables a los directores de prensa quienes, sin exámenes previos de la situación, denunciaban que el país sufría a causa de estos sueldos un "...cáncer que corroe nuestra situación financiera", avaluado en $\$ 100.000 .000$ (p. 343). De modo contrario a estas opiniones, para Edwards no era posible una economía mayor a $\$ 1.670 .000$, si es que no se quería comprometer la marcha de la administración (p. 350).

Edwards planteaba que en Hacienda existían menos empleados que en 1890. En ese departamento se debía trabajar hasta "altas horas de la noche para no atrasar el despacho". En su visión, si en todos los ministerios se hubiese trabajado de esa forma, habría resultado difícil encontrar personas competentes y con preparación especial, como los jefes de sección, interesados en trabajar por $\$ 12.000$, "sin dejarles un momento para ayudarse en las necesidades de una modesta subsistencia" (p. 344).

No habiendo posibilidades de hacer mayores ahorros, Edwards se preguntaba:

"¿Vale la pena arrojar a la calle unos pocos centenares de pobres diablos, en momentos difíciles en que por lo regular no hay trabajo en la industria privada, con el único objeto de disminuir el déficit en una cantidad casi inapreciable?

No; no vale la pena..." (p. 350).

\section{Conclusiones}

Este artículo ha presentado una serie de representaciones en torno a los empleados públicos. Lo que se buscó conocer es cómo eran vistos socialmente por diversos actores, en su mayoría provenientes de una elite social y/o intelectual (en el caso de personas como Juan Rafael Allende o Alejandro Venegas que, no siendo miembros de una elite social, sí tenían un nivel de formación intelectual alto para la época).

Las representaciones analizadas en este artículo muestran que los empleados públicos eran un sector social que no formaba parte de la elite social de la época. El relato que el joven Juan Irrisari hace sobre sobre el baile organizado 
por el Presidente de la República en la década de 1860 deja en claro que los empleados, aunque pudieran coincidir con miembros de la elite social en algunos eventos sociales, no tenían la capacidad de insertarse dentro de las relaciones sociales propias de la elite. De igual forma, este artículo mostró que entre 1880 y 1920 se fue construyendo una imagen del empleado como un tipo con una serie de vicios propios de una vida desordenada (salir de fiesta hasta tarde, levantarse a mediodía y asistir a la oficina solo a conversar), que lo alejaba de una concepción virtuosa o del deber ser de la época.

Igualmente, este artículo mostró que durante la época se consideraba que los empleos públicos se obtenían a partir de favores políticos. Igualmente, se destaca la idea de que la suerte del empleado dependía de la protección que le brindaba una persona influyente. Existía un consenso en que el resultado de esta forma de proveer empleos era que quienes trabajan en las oficinas administrativas del Estado eran incompetentes.

Sí había una disparidad de opiniones en torno a la importancia de la función desarrollada por los empleados. Encina y Pinochet creían que, en general, los empleados no cumplían funciones útiles (para el primero, debido a que el empleado no jugaba un papel en la producción nacional; para el segundo, por la incapacidad y vicios que mostraba). Además, ambos planteaban que quienes ejercían funciones públicas eran inútiles o fracasados, que habían tenido que refugiarse en el empleo público tras fracasar en el ámbito privado.

En cambio, Venegas o Edwards Vives, no tenían una posición tan pesimista sobre el empleado, muy probablemente porque ambos también eran empleados públicos. Para el primero, los vicios de parte de los trabajadores estatales se debían al hecho de ser inquilinos del Estado, lo que los obligaba a actuar corruptamente. En tanto, Edwards Vives destacaba la laboriosidad de los empleados de varias oficinas públicas en las que él había sido jefe.

Tanto la prensa satírica como los ensayistas consideraban que las características negativas que presentaban los empleados respondían al modo de ser chileno, tendiente a la flojera y al deseo de ser empleado público. Para Venegas los vicios de los empleados se debían a los nombramientos políticos y a la precaria situación económica de los trabajadores. En tanto el parasitismo que acusaba Encina, se debía, en su opinión, al tipo de educación imperante en el país. Por su parte, Pinochet consideraba que los vicios de los empleados eran el resultado de las costumbres de una administración reticente al cambio y que aseguraba la estabilidad de los empleados, gracias a la defensa que hacían de ellos sus padrinos políticos.

Otro aspecto importante identificado en este trabajo se refiere a una confrontación entre clases por los puestos administrativos. En los periódicos escritos por Juan Rafael Allende se encuentran varios escritos en los que el 
acceso a los empleos públicos era presentado como una lucha entre dos sectores sociales en pugna. La pregunta para Allende era quién garantizaba un mejor servicio para el país. Para el periodista, la respuesta era la clase media, de la cual él formaba parte. El periodista no fue el único que argumentaba en este sentido. Venegas también lo hacía, desde el momento que acusaba la decadencia del parlamento, que contrastaba con la época en la que patrióticos empleados públicos podían ingresar a esa corporación, en calidad de representantes. Venegas adhería a la tesis de Allende respecto a que el mal ejemplo que las clases altas daban era causante de la fiebre por empleos. La cuestión no es menor pues, tal como muestran los relatos de Allende, los "hijos de" obtenían puestos en la administración, en desmedro de la clase media. Esto hace necesario reinterpretar la tesis del ingreso de los "nuevos hombres" a la administración, destacando que, si bien ello ocurrió, se fue dando en un proceso de transición, en el que convivían -aunque en pugna, según se deriva de los relatos de Allende- diferentes sectores sociales en las oficinas públicas.

\section{Referencias bibliográficas}

\section{Fuentes primarias}

\section{a) Prensa periódica}

Padre Padilla, Santiago, 1884-1896.

El Fígaro, Santiago, 1899-1903.

El Independiente, Santiago, 1886-1887.

El Mercurio, Valparaíso, 1886.

El Pedromón, Santiago, 1901

El Recluta, Santiago, 1891.

La Libertad Electoral, Santiago, 1886.

Poncio Pilatos, Santiago, 1894-1899.

\section{Fuentes secundarias}

a) Artículos

Barría, D. (2009). "En Busca del Mérito: La Discusión Académica en torno a los Empleados Públicos en Chile, 1884-1920", en Estudios Ibero-Americanos, Vol. 35 , No. 2, pp. 148-165. 
De León, C. (1964). "Las capas medias en la sociedad chilena del siglo XIX", en Anales de la Universidad de Chile, No 132, pp. 51-95.

Edwards Vives, A. (1919). "Los empleados públicos", en Pacífico Magazine, Vol. 18, pp. 340-350.

Ibáñez, A. (2003). Herido en el ala. Estado, oligarquías y subdesarrollo. Chile, 1924-1960. Santiago: Biblioteca Americana.

Stabili, M. (2000). "Jueces y Justicia en el Chile liberal". En Carmagnani, M. (Coord.), Constitucionalismo y orden liberal. América Latina 1850-1920, pp. 227-257. Torino: Otto Editore.

\section{b) Libros}

Barros, L., Vergara, X. (1978). El modo de ser aristocrático. Santiago de Chile: Ediciones Aconcagua.

Blest Gana, A. (2005). Martín Rivas. Santiago: Editorial Andrés Bello (1ª Edición 1862).

Echeverría, I. (1942). Cuando mi tierra era niña. Santiago: Nascimento.

Edwards Bello, J. (2004). El Inútil. Santiago: Suma de Letras (1ª Edición 1910).

Encina, F. (1972). Nuestra inferioridad económica. Santiago de Chile: Editorial Universitaria (1ª Edición 1911).

Gazmuri, C. (Ed.). (2001). El Chile del Centenario. Los ensayistas de la crisis. Santiago de Chile: Pontificia Universidad Católica de Chile.

Orrego Luco, L. (1983). Casa Grande. Santiago: Editorial Andrés Bello (1ª Edición 1908).

Pinochet, T. (1915). Un año empleado público en Chile. Santiago de Chile: Imprenta Universitaria.

Subercaseaux, B. (1997). Historia de las Ideas y de la Cultura en Chile. Tomo II Fin de siglo: La época de Balmaceda. Santiago de Chile: Editorial Universitaria.

Venegas, A. (1910). Sinceridad, Chile íntimo en 1910. Santiago de Chile: Imprenta Universitaria. 